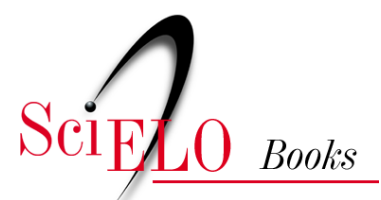

\title{
11. O Ato Médico Através da História
}

\author{
Joffre Marcondes de Rezende
}

\section{SciELO Books / SciELO Livros / SciELO Libros}

REZENDE, J. M. O Ato Médico Através da História. In: À sombra do plátano: crônicas de história da medicina [online]. São Paulo: Editora Unifesp, 2009, pp. 111-119. História da Medicina series, vol. 2. ISBN 978-85-61673-63-5. https://doi.org/10.7476/9788561673635.0012.

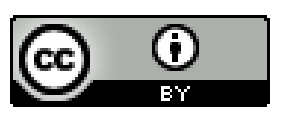

All the contents of this work, except where otherwise noted, is licensed under a Creative Commons Attribution 4.0 International license.

Todo o conteúdo deste trabalho, exceto quando houver ressalva, é publicado sob a licença Creative Commons Atribição 4.0.

Todo el contenido de esta obra, excepto donde se indique lo contrario, está bajo licencia de la licencia Creative Commons Reconocimento 4.0. 


\section{O Ato Médico Através da História*}

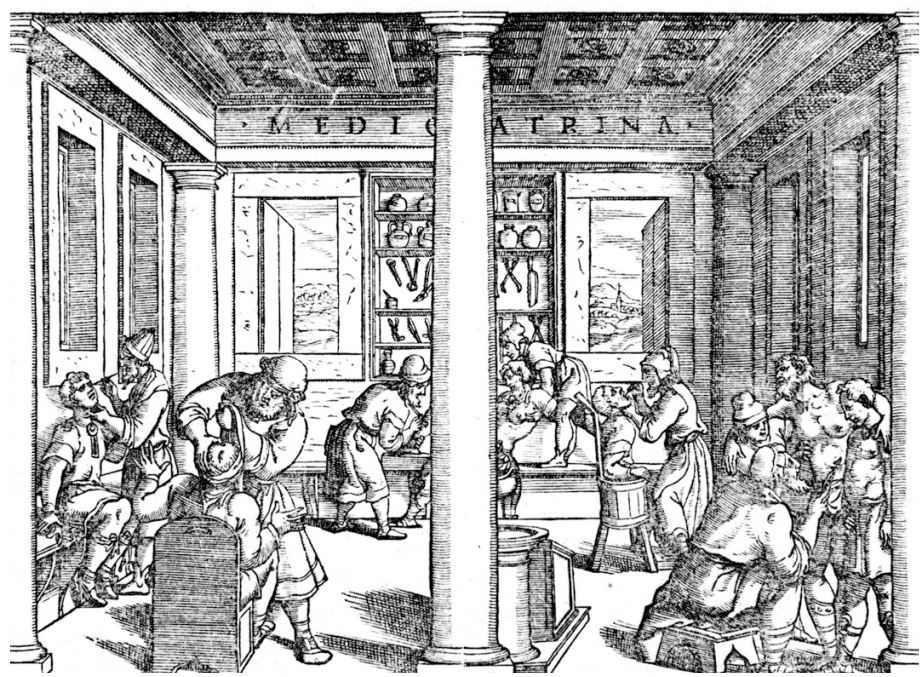

Ilustração de uma edição veneziana das obras de Galeno, publicada em 1550.

\section{Definição e Conceito do Ato Médico}

$\mathrm{O}$ ato médico deve ser definido como todo procedimento da competência e responsabilidade exclusivas do médico no exercício de sua profissão, em benefício do ser humano individualmente ou da sociedade como um todo, visando à preservação da saúde, à prevenção das doenças, à identificação dos estados mórbidos, ao tratamento e à reabilitação do enfermo.

A função principal do médico, em toda a história da humanidade, tem sido a de cuidar e tratar dos enfermos, quando melhor se caracteriza o ato médico. Nesta função o ato médico consiste basicamente na formulação do diagnóstico e na instituição do tratamento mais indicado para o paciente.

* Adaptado da entrevista ao Jornal do Conselho Federal de Medicina, setembro de $200 \mathrm{I}$. 
A formulação do diagnóstico deve fundamentar-se na história clínica passada e presente do paciente, ou seja, na anamnese, no exame físico do paciente, na evolução do quadro clínico e na interpretação crítica dos exames complementares porventura necessários, sejam estes exames de laboratório, registros gráficos ou métodos de imagem. Firmado o diagnóstico sindrômico e, se possível, etiológico, o ato médico seguinte, o de maior responsabilidade, consiste na tomada de decisão quanto à melhor conduta terapêutica a ser seguida, que poderá ser de ordem clínica, cirúrgica, ou mesmo psiquiátrica.

Em muitas ocasiões, o paciente poderá necessitar do concurso de um especialista, ou ser hospitalizado, ou submetido a uma intervenção cirúrgica ou a procedimentos invasivos que encerram algum risco calculado.

Nos casos de tratamento clínico a prescrição é da competência e responsabilidade exclusivas do médico, muito embora a sua execução possa ser efetuada por outro profissional da área de saúde.

Em qualquer caso, o paciente deve receber a orientação e os esclarecimentos necessários sobre a sua doença, respeitando-se a sua autonomia em decidir se aceita ou não as medidas propostas, tanto na fase de elaboração do diagnóstico, quanto do tratamento.

Finalmente, o ato médico mais enaltecedor é o do profissional que reconhece as suas próprias limitações ou dos equipamentos de que dispõe para a condução do caso e encaminha o paciente a um serviço mais bem aparelhado em recursos humanos e técnicos, que possam proporcionar-lhe o que de melhor a medicina possa oferecer-lhe.

$\mathrm{O}$ ato médico, tal como foi conceituado, não deve confundir-se com os procedimentos de outros profissionais que atuam na área de saúde, sejam de nível médio ou superior. O médico se distingue dos demais profissionais da área de saúde por sua formação acadêmica de maior amplitude e abrangência, que o capacita a ter uma visão global do organismo humano em sua totalidade, desde a sua estrutura anatômica ao funcionamento dos diferentes órgãos; a conhecer a natureza dos agentes patogênicos; a ter a percepção de sinais e sintomas que possam indicar alterações da saúde e conduzir ao diagnóstico de uma doença ou de uma lesão inaparente.

Impossível alcançar esta visão sem a aquisição de conhecimentos fundamentais de anatomia normal e patológica, fisiologia, fisiopatologia, farmacologia, semiologia, clínica médica e cirúrgica, doenças infecciosas e 
parasitárias, ginecologia e obstetrícia, pediatria, epidemiologia, medicina preventiva e social, medicina legal e psiquiatria.

Não importa o número e a classificação das disciplinas que compõem a grade curricular do curso médico nas diferentes faculdades; o essencial é que durante o curso de graduação o médico tenha adquirido o lastro de conhecimentos necessários ao exercício da medicina, qualquer que seja a especialidade que escolher. $\mathrm{O}$ especialista, sem esta base comum em sua formação, deixa de ser um médico e passa a ser um técnico. A par disso, espera-se que tenha assimilado durante o curso o comportamento ético e a noção de responsabilidade inerentes à profissão médica e que esteja consciente da necessidade de manter-se permanentemente atualizado, já que a medicina não cessa de progredir e de oferecer novos recursos diagnósticos e terapêuticos.

O desenvolvimento da medicina levou à sua fragmentação em diferentes especialidades. Esta é uma contingência histórica com a qual temos de conviver e saber tirar proveito em favor dos pacientes. Todavia, qualquer que seja a especialidade escolhida ou as habilidades que tenha de adquirir para as tarefas que lhe cabe executar, o médico especialista deverá considerar-se integrante de uma equipe em busca de um diagnóstico ou da melhor conduta terapêutica a ser instituída, compartilhando dos deveres e das responsabilidades de toda a equipe.

Esboça-se atualmente em vários países a política de incentivo à formação do médico geral ou clínico geral no mesmo patamar de valorização do especialista, ou seja, em nível de pós-graduação. Neste sentido, o médico geral seria a primeira instância a quem deveria recorrer o enfermo, que seria encaminhado, sempre que necessário, ao especialista mais indicado.

A participação da enfermeira ou de outro profissional da área de saúde na execução do ato médico não exime o médico da sua inteira e total responsabilidade por qualquer dano causado ao paciente.

\section{Evolução Histórica do Ato Médico}

Nos tempos primitivos, em que a medicina tinha o caráter mágico-sacerdotal, e as doenças eram atribuídas a causas sobrenaturais, $o$ ato médico consistia de magias, ritos e encantamentos de toda ordem, associados a práticas empíricas tradicionais. 
Somente no século v a.C., com o surgimento da medicina hipocrática na Grécia, foi a mesma separada da religião, das crenças irracionais e do apelo ao sobrenatural. Desde então, por caminhos tortuosos, com avanços e recuos, chegou à Idade Média, quando tiveram início os cursos médicos oficiais. Até então, o ensino da arte médica era informal e se fazia de mestre a aluno através das gerações, como consta do juramento de Hipócrates.

Conforme ressaltou Bullough, em seu livro The Development of Medicine as a Profession, a medicina só foi institucionalizada a partir da Idade Média, após a fundação da escola de Salerno e das primeiras universidades europeias (Bullough, I966, pp. 49-72). Dentre elas teve atuação destacada a de Pádua, onde se formaram e ensinaram grandes personagens que revolucionaram a medicina, como Vesalius, Morgagni, Harvey e outros.

Também na medicina árabe do Oriente, que se encontrava em seu apogeu em plena Idade Média, houve preocupação com a institucionalização e fiscalização da profissão médica e, no ano 93 I d.C., as autoridades governamentais promoveram em Bagdá o primeiro exame público para credenciamento dos médicos em exercício. Diz a história que compareceram a este exame 860 candidatos (Major, I954, p. 232).

Embora na Antiguidade clássica, alguns procedimentos cirúrgicos fossem executados por médicos, a cirurgia permaneceu relegada a segundo plano por muitos séculos, entregue a profissionais sem formação acadêmica, os chamados cirurgiões-barbeiros. A Universidade de Paris chegou ao ponto de proibir aos médicos, sob juramento, a prática da cirurgia.

Somente no século XIX, após a descoberta da anestesia geral, a introdução da antissepsia por Lister e a descoberta dos micro-organismos patogênicos responsáveis pela infecção pós-operatória, a cirurgia foi reintegrada à medicina e adquiriu o status de uma de suas mais importantes especialidades.

A separação legal entre a medicina e a farmácia como profissões independentes se processou gradualmente a partir da Idade Média e com características próprias em cada país. Em nenhum caso, entretanto, se atribuiu legalmente ao farmacêutico a prescrição de medicamentos, considerada um ato privativo do médico (Cowen e Helfand, I988, pp. 52-74).

A odontologia, por sua vez, remonta à Antiguidade e sua vinculação à medicina é menos evidente do que no caso da farmácia. A extração de dentes não constituía uma atividade própria dos médicos e sim dos cirurgiões-barbeiros. 
A moderna odontologia teve o seu berço na França, no século XviII, com o médico Pierre Fauchard, cognominado "pai da moderna odontologia", que inovou as técnicas e o instrumental usado pelos dentistas. Viveu de I 678 a I76I, tendo escrito um tratado sobre patologia oral, intitulado Le chirurgien dentiste, que serviu de guia para o desenvolvimento da especialidade no continente europeu (Ring, I998, pp. I60-I73).

As primeiras escolas de odontologia, independentes de cursos ministrados em escolas médicas, foram fundadas no século xix nos Estados Unidos e na França, o que conferiu à odontologia a condição de profissão autônoma de que goza atualmente. Em alguns países, no entanto, como em Portugal e na Itália, a odontologia ainda é considerada uma especialidade médica e o odontólogo deve ser médico antes de se dedicar à odontologia.

O profissional que sempre colaborou com a profissão médica na realização do ato médico é o enfermeiro. É comum nos referirmos à enfermeira em lugar de enfermeiro, tendo em vista o predomínio do sexo feminino na profissão. Sua condição de profissão de nível superior é relativamente recente e teve origem na Inglaterra a partir da fundação da primeira escola de enfermagem por Florence Nightingale, em i 860, após a Guerra da Crimeia (Molina, I973, pp. 58-64).

A profissão de enfermagem tem adquirido crescente prestígio por sua atuação cada vez mais ampla em todos os setores de saúde onde atua, em especial nos estabelecimentos hospitalares. Conta hoje com o concurso de profissionais de nível médio, técnico e auxiliar de enfermagem, podendo dedicar-se a tarefas de maior complexidade e responsabilidade.

As demais profissões da área de saúde têm, todas, uma interface com a medicina, gozando de maior ou menor autonomia de ação em sua área de trabalho, na dependência da legislação e regulamentação vigentes em cada nação.

\section{O Ato Médico no Brasil}

No Brasil, a presença atuante do médico só se tornou realidade no século xix. Lycurgo Santos Filho dá-nos um retrato fiel do que foi a medicina no período colonial.

Pouquíssimos eram os médicos que aqui aportavam. Eram chamados físicos e tidos, em sua maioria, como cristãos-novos, ou seja, judeus 
recém-convertidos ao catolicismo para fugir à Inquisição. Em maior número vieram os cirurgiões, dos quais havia três categorias: os cirurgiões-barbeiros, os cirurgiões aprovados e os cirurgiões diplomados. Predominavam os cirurgiões-barbeiros, que monopolizavam a prática da medicina nos séculos XVI e XVII. Logo os nativos, quase sempre mestiços ou mulatos, aprenderam o ofício e se tornaram também cirurgiões-barbeiros. Sem nenhum preparo, iniciavam-se como aprendizes e após alguma prática eram examinados e recebiam a carta que os habilitava ao exercício da profissão. Praticavam tratamento de fraturas e luxações, curavam feridas, faziam sangria, aplicavam ventosas e sanguessugas e extraíam dentes.

Tiveram papel relevante no atendimento médico à população, tanto indígena como de escravos e colonizadores, os jesuítas e os boticários. Como não havia ainda cursos de farmácia, os boticários aprendiam o ofício nas próprias boticas, prestavam exame perante o físico-mor e recebiam carta de habilitação. Para a manipulação dos remédios, baseavam-se em coleções manuscritas de receitas e, a partir do final do século XvıII, na Farmacopeia Geral de Portugal, impressa em I794. Na ausência de médico, o boticário prescrevia ele mesmo a medicação, tal como ainda hoje ocorre com o farmacêutico nas pequenas localidades do interior.

Além das categorias já mencionadas, havia ainda o barbeiro, o mais humilde dos profissionais. Além do corte de cabelo e barba, fazia sangria, aplicava ventosas, sanguessugas e clisteres, lancetava abscessos e fazia curativos. Era muito procurado pela faixa mais pobre da população. Os partos ficavam entregues às comadres (parteiras sem nenhum preparo) e por toda parte enxameavam os curandeiros e charlatães de toda ordem (Santos Filho, I99I, pp. 52-67).

Esta situação só começou a se modificar com a vinda de d. João vi para o Brasil, quando foram criadas, em I 8०8, as duas escolas médico-cirúrgicas, uma na Bahia e outra no Rio de Janeiro. Na realidade, somente a partir de I 832, quando as duas escolas foram transformadas em faculdades de medicina, começaram a formar médicos brasileiros, os quais, aos poucos, foram assumindo o exercício da medicina em concorrência com os cirurgiões-barbeiros e os curandeiros. As famílias mais abastadas mandavam seus filhos estudar na Europa e muitos médicos brasileiros formaram-se em Coimbra, Salamanca, Montpellier e Edimburgo. 
O número de médicos no Brasil só aumentou no século xx, com a criação de novas escolas médicas. Em I900 havia no país apenas três faculdades de medicina: a do Rio de Janeiro, a de Salvador e a de Porto Alegre, esta última fundada em I 898. Em I950 já eram quinze, que diplomavam cerca de dois mil médicos por ano.

A enfermagem era tradicionalmente exercida pelas irmãs de caridade nas Santas Casas de Misericórdia existentes nas principais cidades e, nos hospitais particulares, por atendentes treinadas em serviço. O curso superior da moderna enfermagem só teve início em I92 I por iniciativa de Carlos Chagas, quando diretor do Departamento Nacional de Saúde, com a fundação da Escola Anna Nery, que serviu de modelo para as demais.

A classe médica, até os anos de I950, sempre se conduziu como profissão liberal, sem tomar consciência da necessidade de se organizar como categoria profissional na defesa de seus mais legítimos interesses e da própria profissão.

A Associação Médica Brasileira, fundada em I95I, tomou iniciativa nesse sentido quando organizou o seu I Congresso na cidade de Ribeirão Preto, em I956, sob a liderança dos professores Hilton Rocha e Jairo Ramos. Houve inicialmente a tentativa de se fundar a Ordem dos Médicos, à semelhança da Ordem dos Advogados, mas a ideia não vingou e foi substituída pela dos Conselhos de Medicina, Federal e Regionais, criados no governo do presidente Juscelino Kubitschek de Oliveira pela lei 3.268, de 30 de setembro de 1957 .

Somente a partir do funcionamento dos conselhos, a classe médica passou a contar com um fórum adequado para discussão das questões éticas da medicina.

\section{A Interface da Medicina com as Demais Profissões da Área de Saúde}

O desenvolvimento da medicina, aliado ao crescimento da população e à maior demanda por serviços públicos e privados de atenção à saúde fez com que surgissem várias outras profissões na área de saúde, além da medicina, farmácia, odontologia e enfermagem.

O número, as denominações e as atribuições de cada uma dessas profissões variam com a legislação de cada país. No Brasil, conforme levantamento 
realizado por Girard e outros, são reconhecidas atualmente catorze categorias de profissionais de nível superior e 43 de nível médio na área de saúde. De nível superior são os médicos, farmacêuticos, odontólogos, enfermeiros, médicos-veterinários, biólogos, biomédicos, nutricionistas, fisioterapeutas, terapeutas ocupacionais, fonoaudiólogos, profissionais em educação física, psicólogos e assistentes sociais.

Das 43 profissões de nível médio que atuam na área de saúde, somente oito têm legislação específica. São elas: técnico em enfermagem, auxiliar de enfermagem, visitador sanitário, técnico em radiologia, técnico em óptica, técnico em laboratório de prótese dentária, massoterapeuta e técnico em segurança do trabalho. As demais foram reconhecidas através de pareceres, resoluções e portarias.

A tendência é de seu número aumentar no futuro, tanto as profissões de nível superior como as de nível médio, em decorrência da subdivisão do trabalho a setores cada vez mais restritos, tal como está acontecendo com as especialidades médicas.

A regulamentação legal das profissões de nível superior de criação mais recente deixam a desejar no tocante aos direitos, atribuições, deveres e limitações dos profissionais nas suas respectivas áreas de atuação. $\mathrm{Na}$ realidade, transferem ao conselho federal e aos conselhos regionais de cada uma delas a competência de promover sua autorregulamentação em seus códigos de ética e resoluções normativas da própria corporação.

Com esta sistemática era de se prever a ocorrência de pontos de atrito por superposição de funções, meios e modos de atuar. Sendo profissões autônomas de nível superior, devem ser consideradas no mesmo nível da profissão médica e não subordinadas a esta, porém com a competência de cada uma delas regulamentada em lei. A definição das atribuições exclusivas do médico está sendo objeto de um projeto de lei em tramitação no Congresso Nacional.

Em nosso entendimento, todas as profissões que atuam na área de saúde são dignas, úteis e necessárias e não surgiram por acaso; são fruto do atual estágio da civilização e muito podem contribuir para o bem-estar da população, tanto na preservação da saúde, como no tratamento e recuperação dos enfermos. Devemos todos trabalhar em harmonia visando ao bem comum. 


\section{Referências Bibliográficas}

Bullough, V. L. The Development of Medicine as a Profession. Basel, S. Karger, I 966.

Cowen, D. L. \& Helfand, W. H. Pharmacy: An Ilustrated History. New York, N. Abrams Inc., I 988.

Girard, S.N.; Fernandes Jr., H. \& Carvalho, C. L. "A Regulamentação das Profissões de Saúde no Brasil”. Disponível em http://www.ccs.uel.br/espacoparasaude/v2ni/RPSB.htm, acesso em 26 ago. 2009

Major, R. H. A History of Medicine. Oxford, Blackwell Scientific Publications, I954.

Molina, T. M. Historia de la Enfermeria. Buenos Aires, Intermedica Ed., I973.

Ring, M. E. História Ilustrada da Odontologia. São Paulo, Manole, I998.

Santos Filho, L. História Geral da Medicina Brasileira. São Paulo, Hucitec/Edusp, I99I. 
